\title{
MicroRNA-130a regulates chondrocyte proliferation and alleviates osteoarthritis through PTEN/PI3K/Akt signaling pathway
}

\author{
YUN ZHANG $^{1 *}$, SHAOCHEN XU $^{1 *}$, ERIC HUANG ${ }^{1}$, HAICHAO ZHOU $^{1}$, \\ BING LI ${ }^{1}$, CHENNI SHAO ${ }^{2}$ and YUNFENG YANG ${ }^{1}$ \\ ${ }^{1}$ Department of Orthopaedics, Shanghai Tongji Hospital; ${ }^{2}$ Shanghai Jiading Nanxiang Hospital, Shanghai 200065, P.R. China
}

Received January 2, 2017; Accepted February 16, 2018

DOI: $10.3892 /$ ijmm.2018.3551

\begin{abstract}
The function of microRNA-130a in development and progression of osteoarthritis was determined. In osteoarthritis patients, the serum levels of microRNA-130a were decreased, compared with normal group. Overexpression of microRNA-130a increased cell proliferation and decreased apoptosis of chondrocytes, and downregulation of microRNA-130a also decreased cell proliferation and induced apoptosis in chondrocytes. Downregulation of microRNA-130a promoted Bax and caspase-3/9 protein expression, increased inflammation divisors and suppressed the PTEN/PI3K/Akt signaling pathway. PTEN inhibitor, VO-Ohpic trihydrate increased the destructive effect of microRNA-130a on cell proliferation of chondrocytes. PI3K inhibitor, wortmannin also increased the destructive effect of microRNA-130a on osteoarthritis. In conclusion, microRNA-130a is an important regulator of osteoarthritis in chondrocytes through PTEN/ PI3K/Akt signaling pathway.
\end{abstract}

\section{Introduction}

Rheumatoid arthritis (RA) is a chronic autoimmune disease that is associated with high morbidity and high disability rate. Pathogenesis of RA has not been illuminated yet (1), thus, exploring the pathophysiological process of RA synovial proliferation is an urgent problem to be solved (2). The pathological manifestations of RA include recurrent attacks of inflammation, excessive proliferation and dysfunction of synovial tissues, invasion and destruction of articular cartilage and bone by synoviocytes and vascular cells (3). At the initial

Correspondence to: Professor Yunfeng Yang, Department of Orthopaedics, Shanghai Tongji Hospital, 389 Xincun Road, Putuo, Shanghai 200065, P.R. China

E-mail: yyfscn@163.com

${ }^{*}$ Contributed equally

Key words: microRNA-130a, osteoarthritis, PTEN/PI3K/Akt, chondrocytes stage of RA, inflammatory cells aggregate to the articular cavity under the action of inflammatory mediators and chemokines, and generate inflammatory response targeting the synovial membrane (4). Macrophage-like synoviocytes and fibroblast-like synoviocytes will produce a large amount of inflammatory cytokines and matrix degrading enzymes under incentive conditions, maintain and promote the persistence of inflammatory response, promote angiogenesis, and induce destruction of joint tissue (5).

It is known that autoimmune disorder can induce RA, but the cause of such disturbance remains unclear (6). microRNA, which is most promising in research in this direction, is an important component in the cellular and genetic regulatory network (7). It is a kind of endogenous and tiny non-coding single-strand RNA molecule with the average length of 22 nucleotides, which has become the hot research direction in immunology at present as a result of its diversified species and important roles (8). It plays an important role in processes such as hematopoiesis, proliferation, apoptosis, tissue differentiation and organ differentiation (9). In addition, it is suggested in a recent study to be involved in regulating body immune system (9). Currently, increasing literature illustrates the huge potential of microRNA at fundamental and clinical levels, especially as the therapeutic targets, inserted molecules and biomarkers (9). It is been known that the functions of microRNA in animals are not restricted to the regulation of cell proliferation and differentiation, lipid conversion, and hormone secretion regulation. More importantly, it can prevent disturbance of normal immune function (8). Jiang and Wang (10) indicated that histone deacetylase 3 was involved in ankylosing spondylitis via miR-130a and enhancement of tumor necrosis factor-1 $\alpha$ (TNF-1 $\alpha$ ) expression. Li et al (11) showed that miR-130a played an important role in regulating the expression of TNF- $\alpha$ in osteoarthritis.

Akt, which is overexpressed in RA synoviocytes, can not be detected in normal synoviocytes (12). Addition of Akt in RA synoviocytes cultured in vitro endows cells with the ability to act against apoptosis, suggesting that the PI3K/Akt signal pathway, which is highly active in RA, may be involved in the course of RA (12). PTEN is an important negative regulatory factor in PI3K/Akt signal pathway, which can downregulate the activities of pathway as well as its downstream factors at multiple levels (13). This characteristic has been verified in 
numerous studies on tumor (13). Research on RA suggests that PTEN may also be involved in activating the pathway (13). Expression quantity of PTEN is lower than normal level in lining layer of affected joints, but it is normal in the sub-lining layer and can hardly be detected in invasive RA synoviocytes, indicating certain association between PTEN afunction and the highly activated PI3K/Akt in RA (14). Therefore, expressing PTEN protein in the pathway, targeting Akt mRNA sequence, upregulating PTEN or downregulating Akt can inhibit the pathway activity, which thus inhibits FLS proliferation, promotes its apoptosis and delays injury in affected joints (15). In this study, we sought to determine how microRNA-130a regulates osteoarthritis.

\section{Materials and methods}

Patients. The serum levels of patients with osteoarthritis $(\mathrm{n}=6$, male, 55.45 \pm 5.23$)$ and healthy volunteers $(n=6$, male, 50.56 \pm 7.62 ) were obtained from the department of Orthopaedics, Shanghai Tongji Hospital at the time of total knee replacement surgery. Ten milliliters of peripheral blood was collected and centrifuged at $2,000 \mathrm{x}$ g for $10 \mathrm{~min}$ at $4^{\circ} \mathrm{C}$. Serum samples were collected and saved at $-80^{\circ} \mathrm{C}$. This study was carried out in accordance with the approved guidelines of Shanghai Tongji Hospital and was approved by the Ethics Committee of Shanghai Tongji Hospital.

$R T-P C R$. Total RNA was isolated from serum samples and cell samples using TRIzol regent, and samples were treated with DNase I (both from Invitrogen, USA). cDNA was performed using oligo $(\mathrm{dT})_{20}$ and Superscript II reverse transcriptase (Invitrogen). Real-time PCR was performed using a StepOnePlus Real-time PCR system (Applied Biosystems, Foster City, CA, USA) with an ABI 7500 quantitative PCR instrument. The primer sequences were as follows: U6 forward, 5'-CTCGCTTCGGCAGCACA-3' and reverse, 5'-ACGCTTCA CGAATTTGCGT-3'; miR-130a, 5'-CAGUGCAAUGUUAA AAG-3'. PCR cycling conditions were as follows: $95^{\circ} \mathrm{C}$ for $10 \mathrm{~min}, 40$ cycles of $94^{\circ} \mathrm{C}$ for $30 \mathrm{sec}, 55^{\circ} \mathrm{C}$ for $30 \mathrm{sec}, 60^{\circ} \mathrm{C}$ for $10 \mathrm{sec}$, and a final extension at $72^{\circ} \mathrm{C}$ for $30 \mathrm{sec}$. The $2^{-\Delta \Delta \mathrm{Ct}}$ method was used to represent microRNA-130a expression.

Cell isolation, culture conditions, and cell transfection. The use of animals was approved by the Ethics Committee of Shanghai Tongji Hospital. Male SD rats (220-250 g, 8-9 weeks) were obtained from Shanghai Slick Experimental Animal Co., Ltd. (Shanghai, China) and housed at $22-23^{\circ} \mathrm{C}, 55-60 \%$ humidity, 7:00-19:00. The cartilage tissues were acquired, washed with phosphate-buffered saline (PBS), sterilized with $75 \%$-ethyl alcohol and cut into pieces using micro-scissors. The tissues were digested with $0.25 \%$ Trypsin-EDTA for $30 \mathrm{~min}$ on ice, then digested with collagenase II (both from Invitrogen) for $4 \mathrm{~h}$ on ice and then filtered using 200-mesh sieve. Chondrocytes were cultured with Dulbecco's modified Eagle's medium (DMEM) with high-dose (4.5 g/l) glucose, $10 \%$ fetal bovine serum (FBS), and $1 \%$ penicillin/streptomycin at $37^{\circ} \mathrm{C}$ with $5 \% \mathrm{CO}_{2}$. The microRNA-130a mimics, microRNA-130a inhibitors and their negative controls (NC) were purchased from Sangon Biotech Co., Ltd. (Shanghai, China). MicroRNA-130a inhibitors and VO-Ohpic trihydrate
(10 nM, PTEN inhibitor) or wortmannin ( $2 \mathrm{nM}, \mathrm{PI} 3 \mathrm{~K}$ inhibitor) were added into cells for $48 \mathrm{~h}$.

3-(4,5-Dimethylthiazol-2-yl)-2,5-diphenyltetrazolium bromide (MTT) assay. After transfection or inhibitor treatment, $10 \mu \mathrm{l}$ MTT (5 mg/ml; Invitrogen) was added into cultured medium for $4 \mathrm{~h}$ at $37^{\circ} \mathrm{C}$. After the removal of culture medium, dimethyl sulphoxide (150 $\mu \mathrm{l}$; Invitrogen) was added to each well, leaving the cells at room temperature in the dark for $20 \mathrm{~min}$, and absorbance at $570 \mathrm{~nm}$.

Apoptosis assay. After inhibitor treatment, cells were washed three times with PBS and resuspend using buffer (BD Biosciences, San Jose, CA, USA). Cells was stained using the $5 \mu \mathrm{l}$ of Annexin V-FITC and $5 \mu \mathrm{l}$ of PI double (BD Biosciences) for $15 \mathrm{~min}$ in the dark at room temperature. Flow cytometry (FACSCanto ${ }^{\mathrm{TM}}$ ) was used to measure apoptosis rate, and analyzed using CellQuest Pro software (both from BD Biosciences). Then enzyme-linked immunosorbent assay (ELISA) assay was performed. After inhibitor treatment, supernatant of all the cells was collected and used to measure interleukin-1 $\beta$ (IL-1 $\beta$ ), IL-6 and IL-18 levels using ELISA kits (Nanjing Jiancheng Biology Engineering Institute, Nanjing, China). Plates were read using a Multiskan Go Microplate Spectrophotometer (Thermo Fisher Scientific) at $450 \mathrm{~nm}$.

Western blot analysis. After transfection, cell was lysed in lysis buffer on ice for $30 \mathrm{~min}$, followed by a 12,000 rpm centrifugation at $4^{\circ} \mathrm{C}$ for $10 \mathrm{~min}$. The amount of BCA detection reagent needed was calculated according to protein content. Proteins were resolved on an $8-10 \%$ sodium dodecyl sulfate-polyacrylamide gel electrophoresis (SDS-PAGE) and transferred to PVDF membranes (Millipore, Billerica, MA, USA). Membranes were blocked with 5\% nonfat milk in Tris-buffered saline and were incubated with primary antibodies against: Bax (sc-6236,1:500), caspase-3 (sc-98785, 1:500), caspase-9 (sc-8355, 1:500), PTEN (sc-6817-R, 1:500), PI3K (sc-7174, 1:500), p-Akt (sc-33437, 1:500) and glyceraldehyde 3-phosphate dehydrogenase (GAPDH) (sc-367714, 1:2,000) at $4^{\circ} \mathrm{C}$ overnight. After washing with TBST, membranes were detected using HRP-conjugated secondary anti-rabbit antibodies (7074, 1:5,000; Cell Signaling Technology, Inc.) and The band was visualized with an enhanced chemiluminescence kit and analyzed using AlphaEaseFC 4.0 software.

Statistical analysis. Results are expressed as the mean \pm SD. Data were analyzed between two groups using the Student's t-test, while among more than two groups by the One-way ANOVA method. $\mathrm{P}<0.05$ provided evidence of significant differences.

\section{Results}

The serum levels of microRNA-130a in osteoarthritis patients. To identify the function of microRNA-130a in development and progression of osteoarthritis, microRNA-130a expression was surveyed by RT-PCR. As shown in Fig. 1, the serum levels of microRNA-130a were decreased, compared with normal group. 


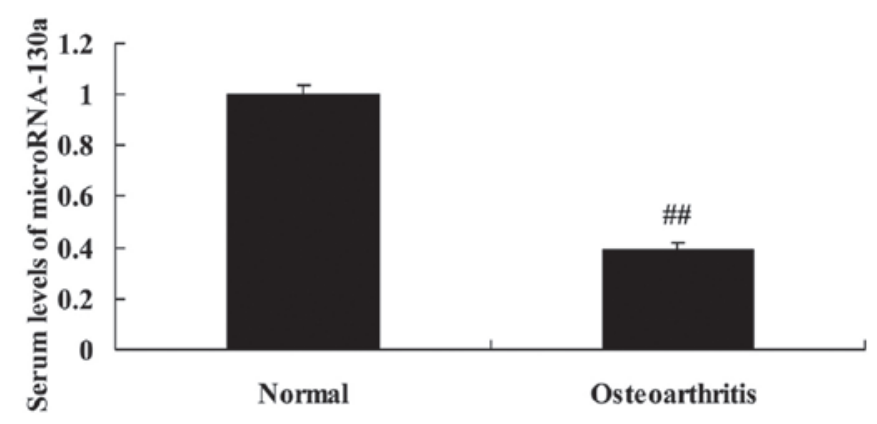

Figure 1. The serum levels of microRNA-130a in osteoarthritis patients. ${ }^{\#} \mathrm{p}<0.01$ compared with normal group.

Overexpression of microRNA-130a increased cell proliferation and decreased apoptosis of chondrocytes. Interestingly, we used microRNA-130a mimics to increase microRNA-130a expression for the function of microRNA-130a on osteoarthritis. Fig. 2 showed that microRNA-130a mimics effectively increased microRNA-130a expression. Overexpression of microRNA-130a increased cell proliferation and decreased apoptosis of chondrocytes (Fig. 2).

Downregulation of microRNA-130a also decreased cell proliferation and induced apoptosis in chondrocytes. Next, we also used anti-microRNA-130a mimics to decrease microRNA-130a expression for the function of microRNA-130a on osteoarthritis. Similar to the results of Fig. 3, anti-microRNA-130a mimics effectively decreased microRNA-130a expression, however, downregulation of microRNA-130a also decreased cell proliferation and induced apoptosis in chondrocytes (Fig. 3).

Downregulation of microRNA-130a promoted Bax and caspase-3/9 protein expression in chondrocytes. We tested the hypothesis that the downregulation of microRNA-130a on anticancer effects in osteoarthritis. Notably, downregulation of microRNA-130a significantly promoted Bax and caspase-3/9 protein expression in chondrocytes (Fig. 4).

Downregulation of microRNA-130a increases inflammation divisors in chondrocytes. To directly test the hypothesis that osteoarthritis-induced inflammation divisors is a downstream target of microRNA-130a, IL-1 $\beta$, IL-6 and IL-18 levels were measured in this study. There was a significant increases of IL-1 $\beta$, IL- 6 and IL-18 levels in chondrocytes by microRNA-130a downregulation, compared with negative control group (Fig. 5).

Downregulation of microRNA-130a increased PTEN/PI3K/Akt signaling pathway in chondrocytes. We investigated which of PTEN/PI3K/Akt signaling pathways regulates the function of microRNA-130a on osteoarthritis. Compared with negative control group, the downregulation of microRNA-130a significantly increased PTEN protein expression and suppressed PI3K and p-Akt protein expression in chondrocytes (Fig. 6). Summarily, osteoarthritis patients have alterations in microRNA-130a expression, and microRNA-130a may regulate osteoarthritis.

PTEN inhibitor decreased the destructive effect of microRNA-130a on PTEN/PI3K/Akt signaling pathway of chondrocytes. In contrast, we used VO-Ohpic trihydrate, PTEN inhibitor, was used to inhibit PTEN expression in chondrocytes after microRNA-130a downregulation. PTEN inhibitor significantly suppressed PTEN protein expression, and induced PI3K and p-Akt protein expression chondrocytes after microRNA-130a downregulation (Fig. 7).

PTEN inhibitor decreases the destructive effect of microRNA-130a on cell proliferation of chondrocytes. We
A
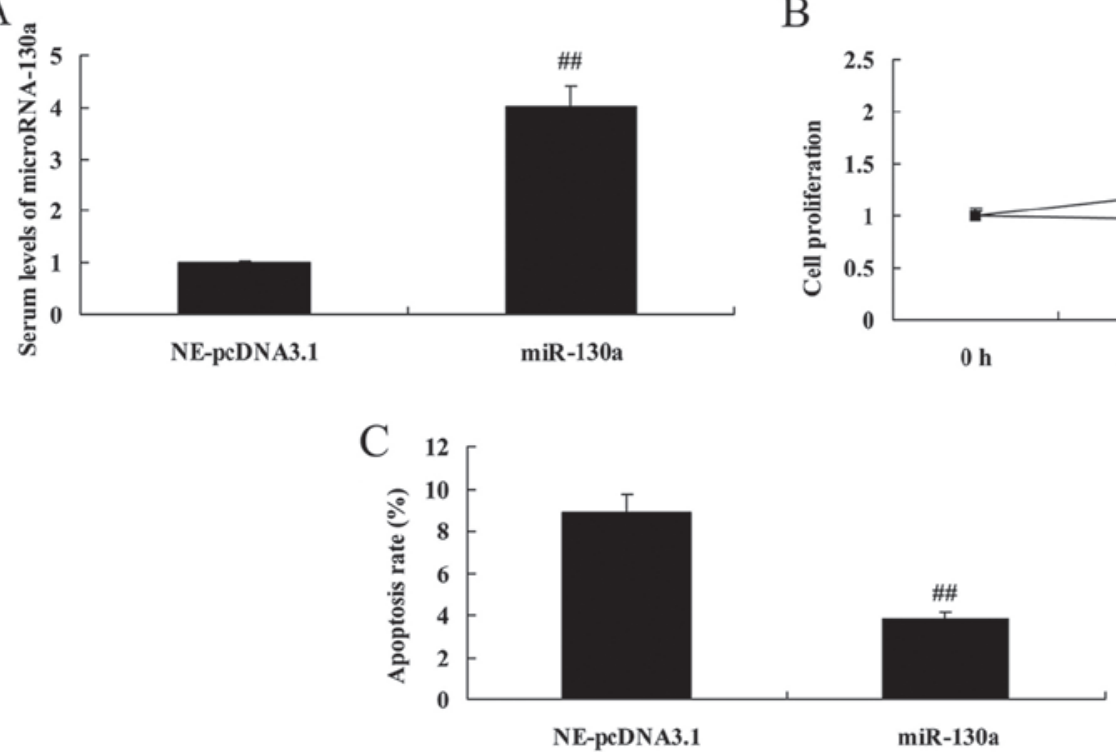

B

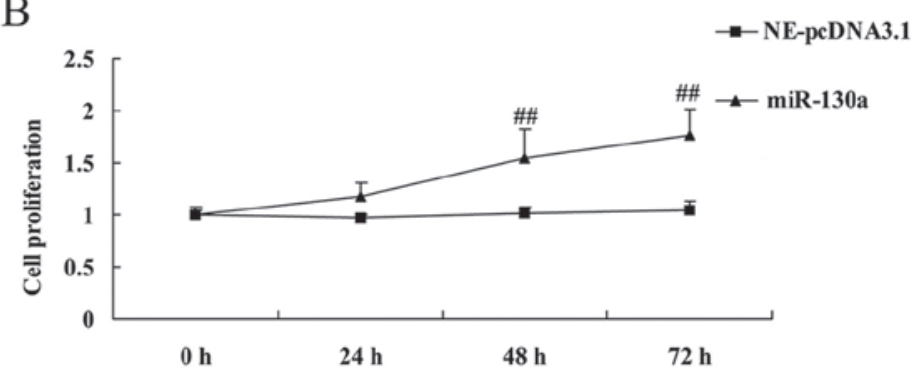

Figure 2. Overexpression of microRNA-130a increased cell proliferation and decreased apoptosis of chondrocytes. MicroRNA-130a expression (A), cell proliferation (B) and apoptosis (C) of chondrocytes. ${ }^{\# \#} \mathrm{p}<0.01$ compared with negative group. Ne-pcDNA3.1, negative group; miR-130a, microRNA-130a mimics group. 

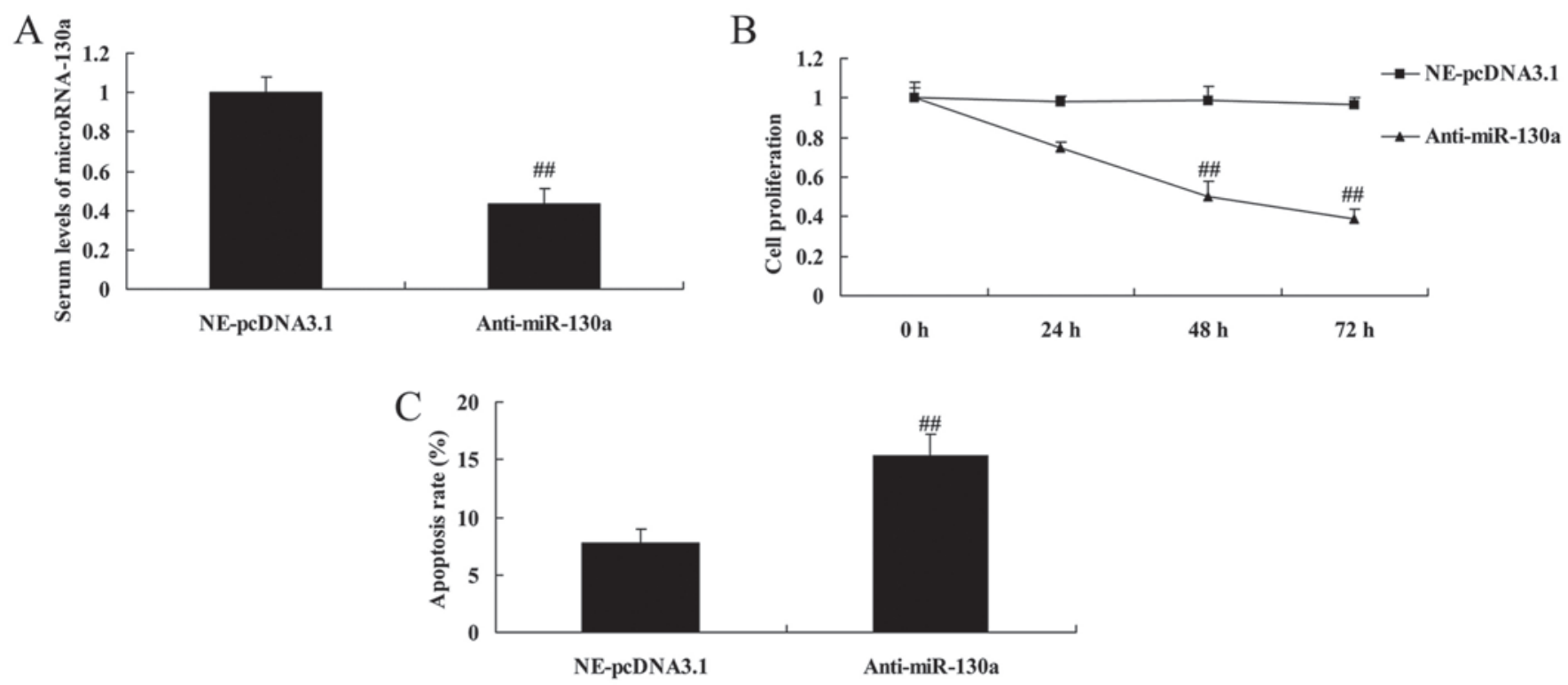

Figure 3. Downregulation of microRNA-130a decreases cell proliferation and induces apoptosis in chondrocytes. MicroRNA-130a expression (A), cell proliferation (B) and apoptosis (C) of chondrocytes. ${ }^{\#} \mathrm{p}<0.01$ compared with negative group. Ne-pcDNA3.1, negative group; anti-miR-130a, anti-microRNA-130a mimics group.

A
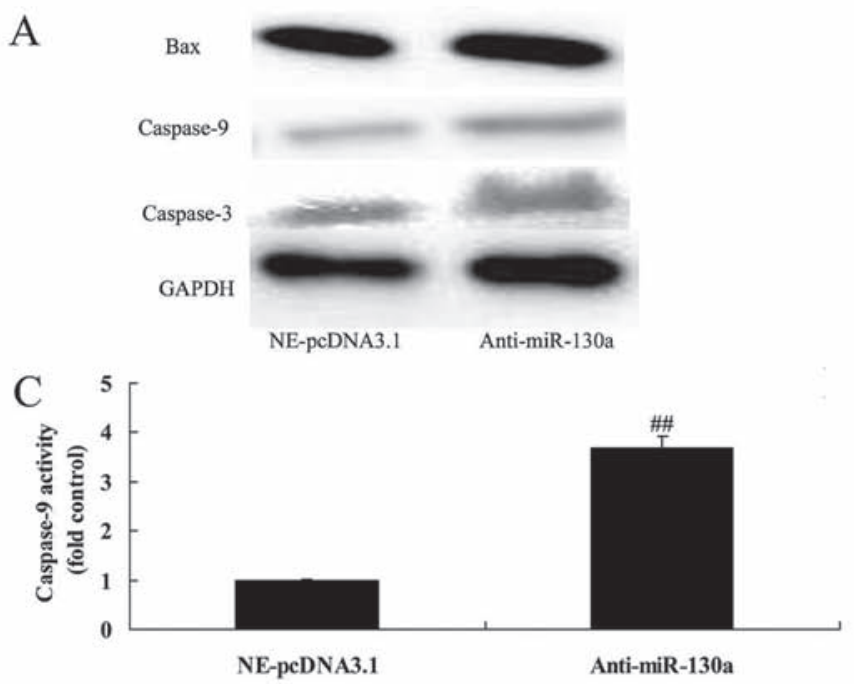

B

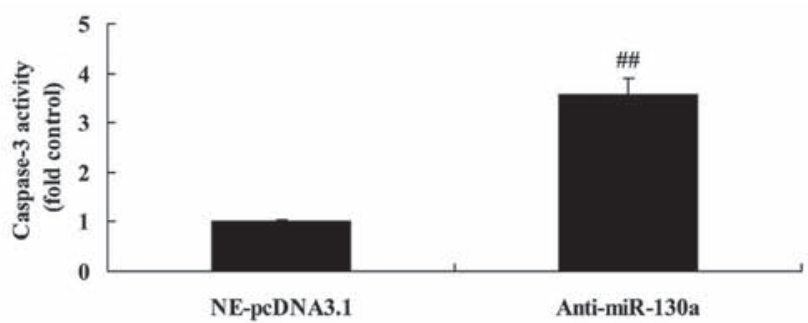

$\mathrm{D}$

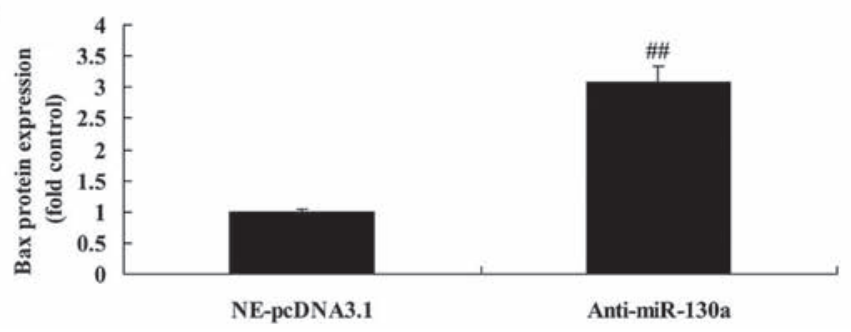

Figure 4. Downregulation of microRNA-130a promotes Bax and caspase-3/9 protein expression in chondrocytes. Downregulation of microRNA-130a promoted Bax and caspase-3/9 protein expression using western blotting (A) and statistical analysis for Bax (B) and caspase-3/9 (C and D) protein expression in chondrocytes. ${ }^{\# \#}$ p $<0.01$ compared with negative group. Ne-pcDNA3.1, negative group; anti-miR-130a, anti-microRNA-130a mimics group.

assessed whether PTEN participates in the function of microRNA-130a on osteoarthritis. PTEN inhibitor significantly promoted cell proliferation, decreased apoptosis, and suppressed Bax and caspase-3/9 protein expression in chondrocytes after microRNA-130a downregulation (Fig. 8).

PTEN inhibitor decreases the destructive effect of microRNA-130a on inflammation divisors of chondrocytes. We analyzed whether PTEN participates in the function of microRNA-130a on inflammation divisors of osteoarthritis. As showed in Fig. 9, PTEN inhibitor significantly reduced IL-1 $\beta$, IL- 6 and IL-18 levels in chondrocytes after microRNA-130a downregulation. Furthermore, PTEN regulates microRNA-130a effect on osteoarthritis.
Wortmannin increases the destructive effect ofmicroRNA-130a on PI3K/Akt signaling pathway of chondrocytes. We further clarified the molecular mechanism underlying the suppressive effect of microRNA-130a on osteoarthritis. PI3K inhibitor, wortmannin, significantly suppressed PI3K and p-Akt protein expression in chondrocytes after microRNA-130a downregulation (Fig. 10).

Wortmannin increases the destructive effect of microRNA-130a on cell proliferation of chondrocytes. In order to determine the function of PI3K on microRNA-130a in osteoarthritis, we revealed cell proliferation of chondrocytes. As showed in Fig. 11, the inhibition of PI3K significantly decreased cell proliferation, increased apoptosis, and induced 

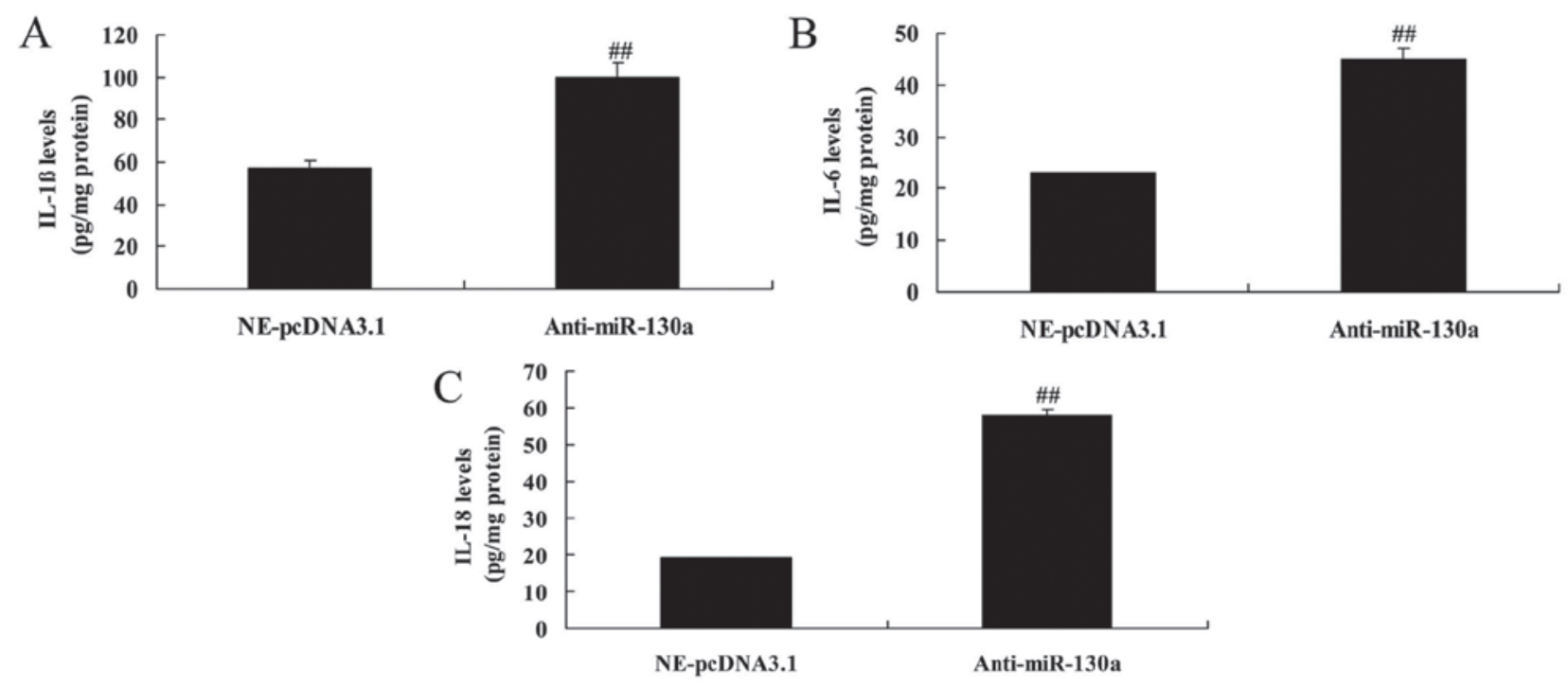

Figure 5. Downregulation of microRNA-130a increases inflammation divisors in chondrocytes. Interleukin-1 (IL-1 $\beta$ ) (A), IL-6 (B) and IL-18 (C) levels ${ }^{\# \#} \mathrm{p}<0.01$ compared with negative group. Ne-pcDNA3.1, negative group; anti-miR-130a, anti-microRNA-130a mimics group.

A
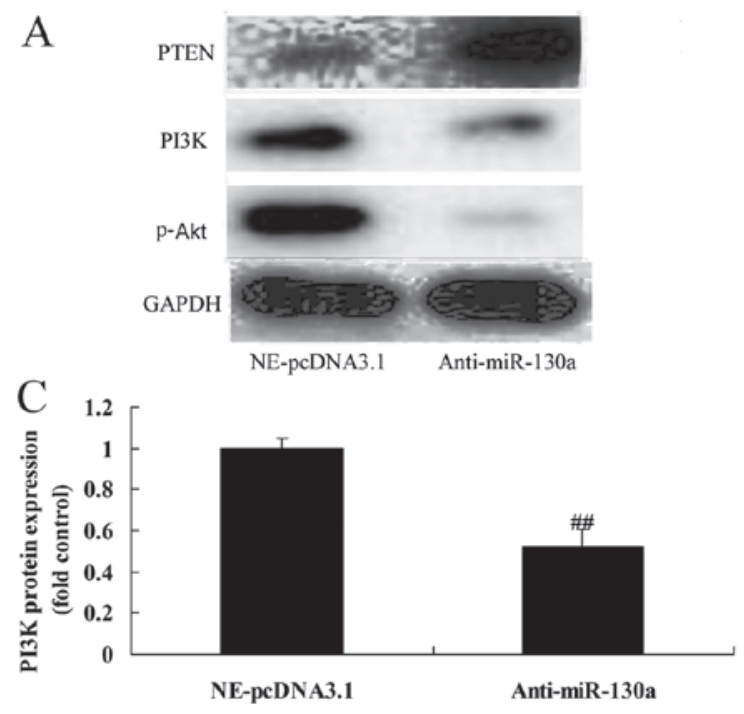

$\mathrm{B}$
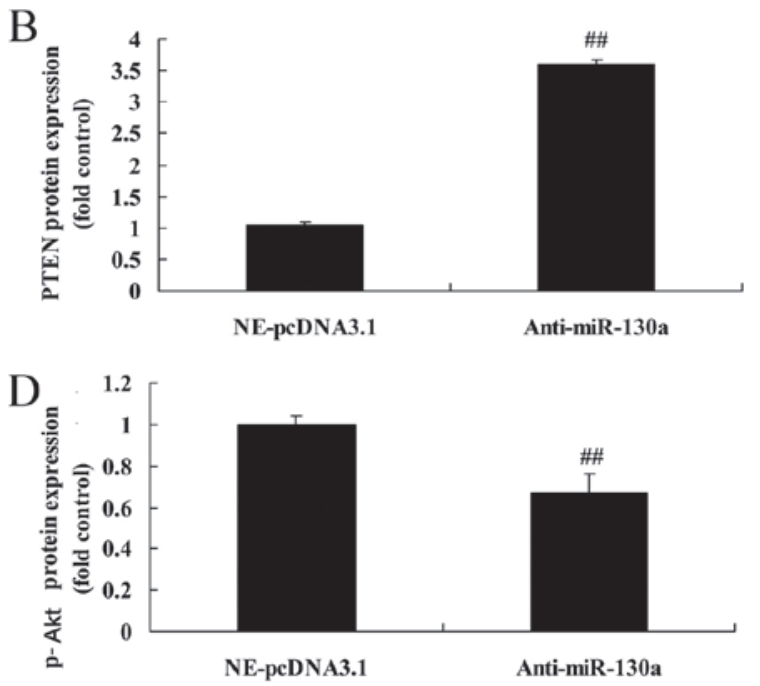

Figure 6. Downregulation of microRNA-130a suppresses PTEN/PI3K/Akt signaling pathway in chondrocytes. Downregulation of microRNA-130a suppressed PTEN, PI3K and p-Akt protein expression using western blotting (A) and statistical analysis for PTEN (B), PI3K (C) and p-Akt (D) protein expression in chondrocytes. ${ }^{\# \#} \mathrm{p}<0.01$ compared with negative group. Ne-pcDNA3.1, negative group; anti-miR-130a, anti-microRNA-130a mimics group.

Bax and caspase-3/9 protein expression in chondrocytes after microRNA-130a downregulation.

Wortmannin increases the destructive effect of microRNA-130a on inflammation divisors of chondrocytes. We then examined the inhibition of PI3K on the function of microRNA-130a on IL-1 $\beta$, IL- 6 and IL-18 levels. Interestingly, the inhibition of PI3K significantly reduced IL-1 $\beta$, IL-6 and IL-18 levels in chondrocytes after microRNA-130a downregulation (Fig. 12). Taken together, PI3K/Akt signaling pathway participates in the function of microRNA-130a on inflammation in osteoarthritis.

\section{Discussion}

Present study generally focuses on the molecular mechanisms by which RA initiates and develops; for instance, expression, activity and function of disease-related factors under specific tissue, cell and physiopathological conditions, as well as function, regulation and signal communication of relevant signal pathways (16). Illuminating the mechanism that drives abnormal activities or functions of cytokines, signal pathways and cells is an important component in research on RA (17). As is commonly suggested at present, RA is induced by imbalance of cellular and molecular network, which gives rise to abnormal expression and activities of cytokines [such as TNF- $\alpha$, IL-1, IL-6 and nuclear factor- $\kappa \mathrm{B}(\mathrm{NF}-\kappa \mathrm{B})]$, proteins and enzyme systems (like FAK, shC and MMPS) (18). In this study, we found that the serum levels of microRNA-130a were decreased. Overexpression of microRNA-130a increased cell proliferation and decreased apoptosis of chondrocytes, and downregulation of microRNA-130a also decreased cell 
A
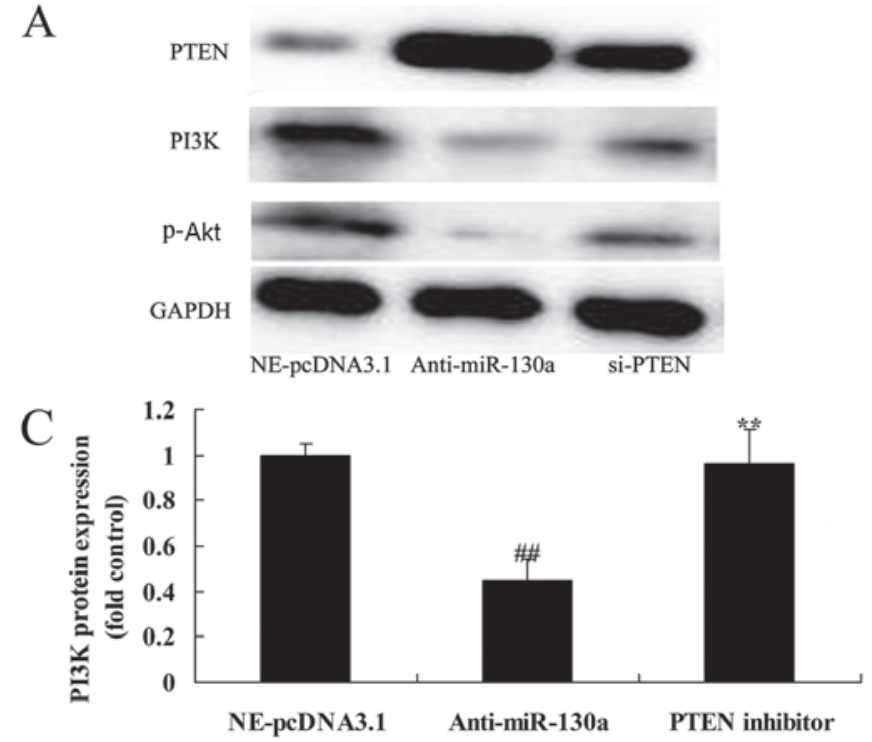
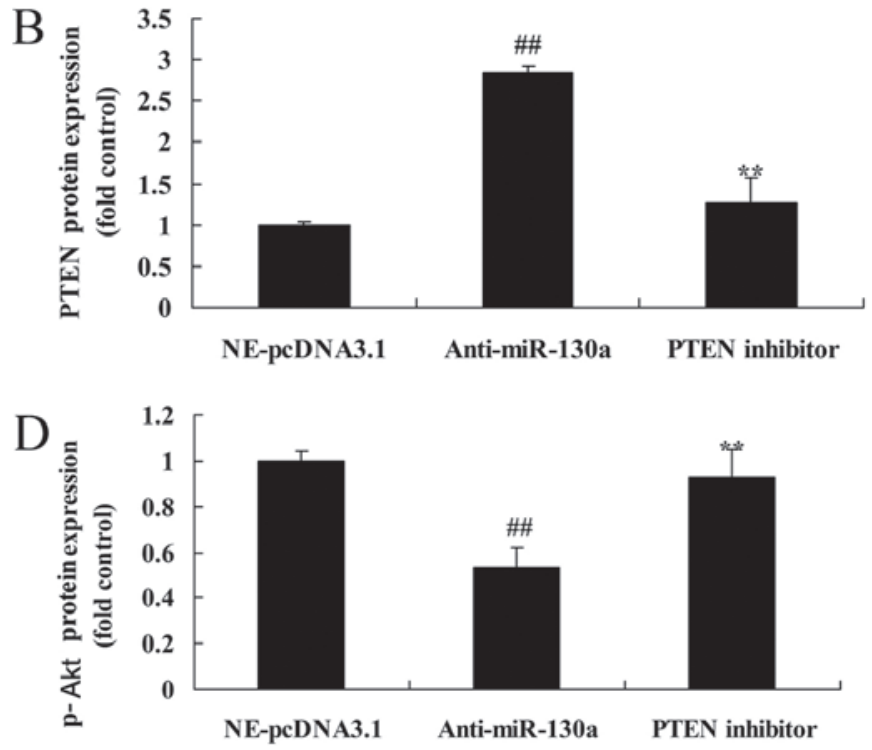

Figure 7.PTEN inhibitor decreases the destructive effect of microRNA-130a on PTEN/PI3K/Akt signaling pathway of chondrocytes. PTEN inhibitor increased the destructive effect of microRNA-130a on PTEN, PI3K and p-Akt protein expression using western blotting (A) and statistical analysis for PTEN (B), PI3K (C) and p-Akt (D) protein expression in chondrocytes. ${ }^{\# \#} \mathrm{p}<0.01$ compared with negative group; ${ }^{* *} \mathrm{p}<0.01$ compared with anti-microRNA-130a mimics group. Ne-pcDNA3.1, negative group; anti-miR-130a, anti-microRNA-130a mimics group; si-PTEN, PTEN inhibitor group.
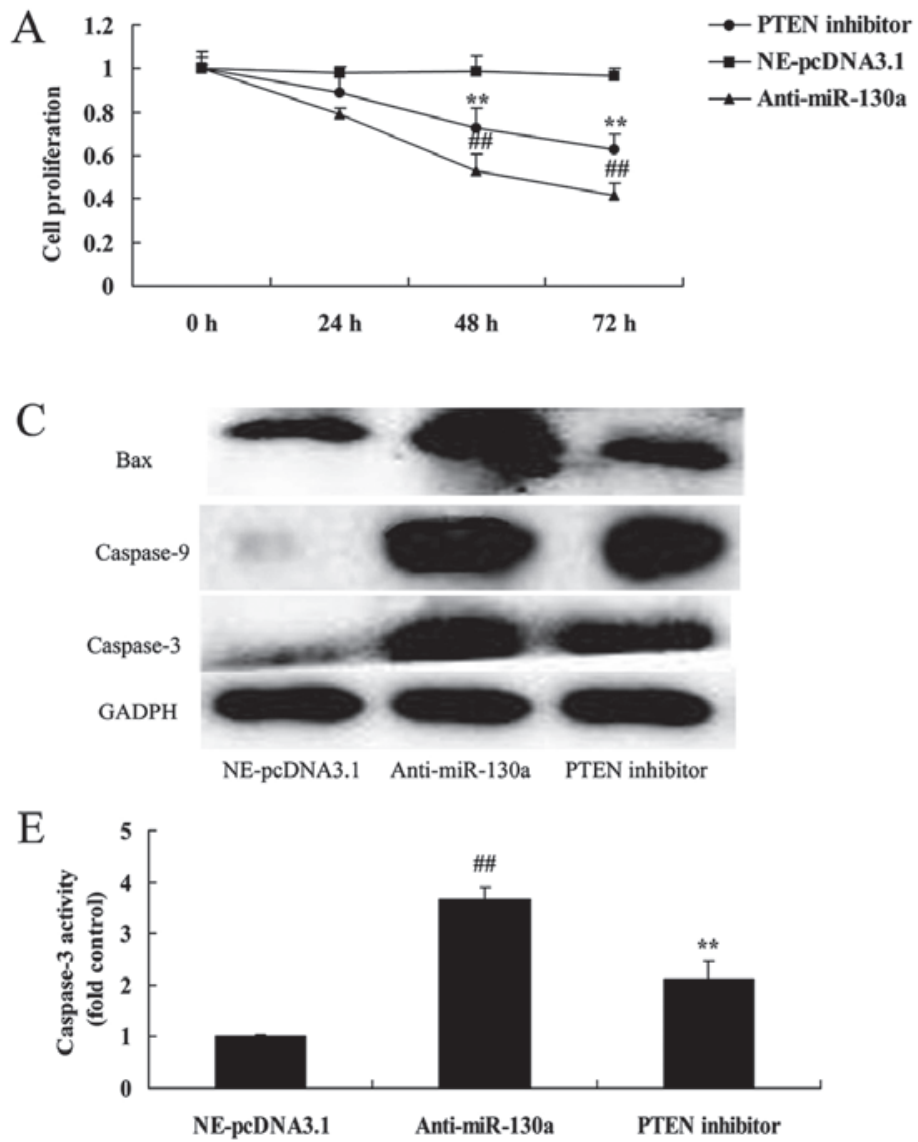
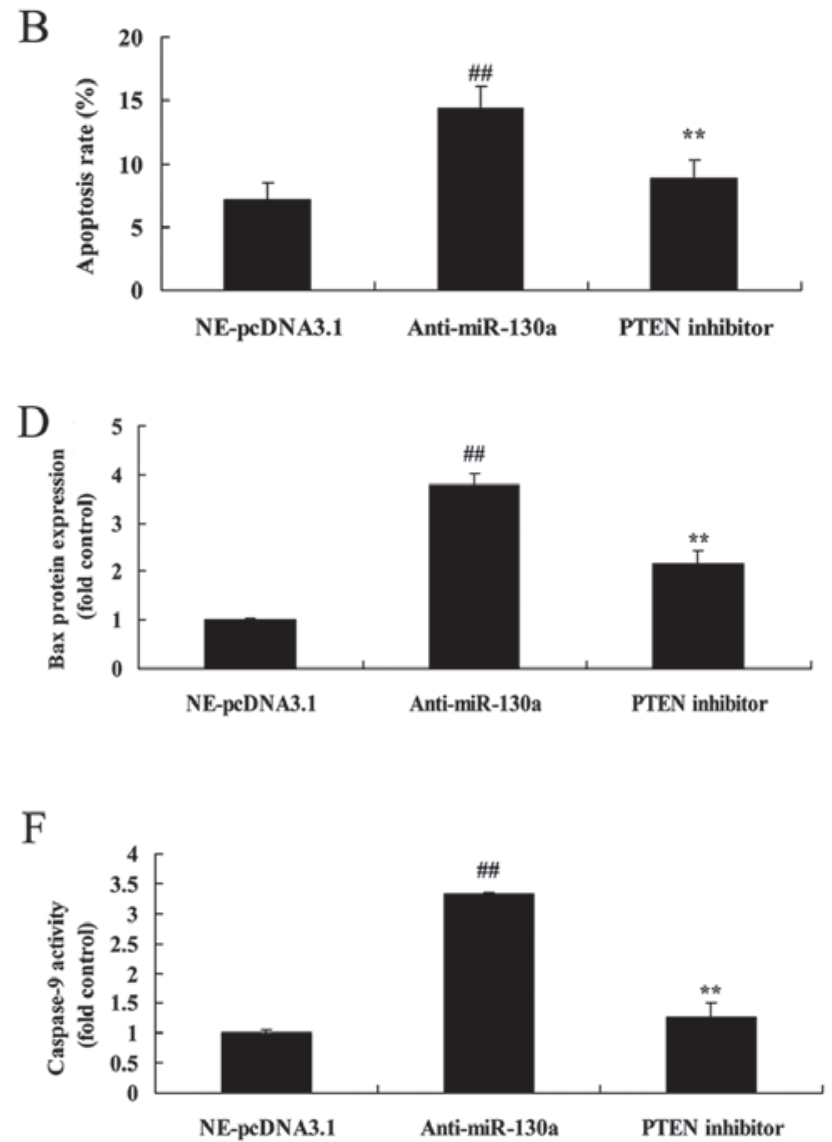

Figure 8. PTEN inhibitor decreases the destructive effect of microRNA-130a on cell proliferation of chondrocytes. PTEN inhibitor increased the destructive effect of microRNA-130a on cell proliferation (A), apoptosis (B), Bax and caspase-3/9 protein expression using western blotting (C) and statistical analysis for Bax (D) and caspase-3/9 (E and F) protein expression in chondrocytes. ${ }^{\# \#} \mathrm{p}<0.01$ compared with negative group; ${ }^{* *} \mathrm{p}<0.01$ compared with anti-microRNA-130a mimics group. Ne-pcDNA3.1, negative group; anti-miR-130a, anti-microRNA-130a mimics group; si-PTEN, PTEN inhibitor group.

proliferation and induced apoptosis in chondrocytes. Zumbrennen-Bullough et al suggested that microRNA-130a is upregulated suppresses hepcidin synthesis, and thereby promotes iron availability through BMP and ALK2 (19). 

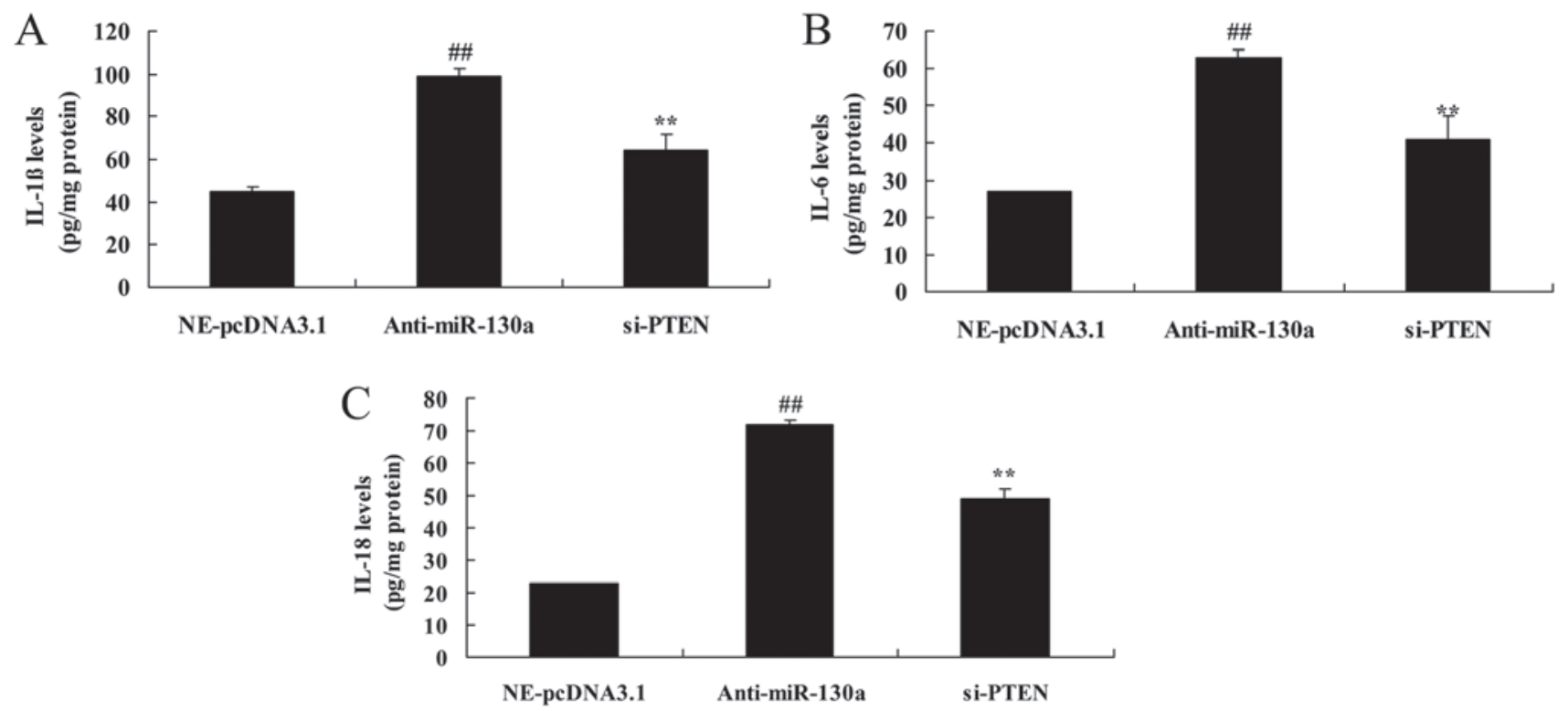

Figure 9. PTEN inhibitor decreases the destructive effect of microRNA-130a on inflammation divisors of chondrocytes. Interleukin-1 $\beta$ (IL-1 $\beta$ ) (A), IL-6 (B) and IL-18 (C) levels. ${ }^{\#} \mathrm{p}<0.01$ compared with negative group; ${ }^{* *} \mathrm{p}<0.01$ compared with anti-microRNA-130a mimics group. Ne-pcDNA3.1, negative group; anti-miR-130a, anti-microRNA-130a mimics group; si-PTEN, PTEN inhibitor group.
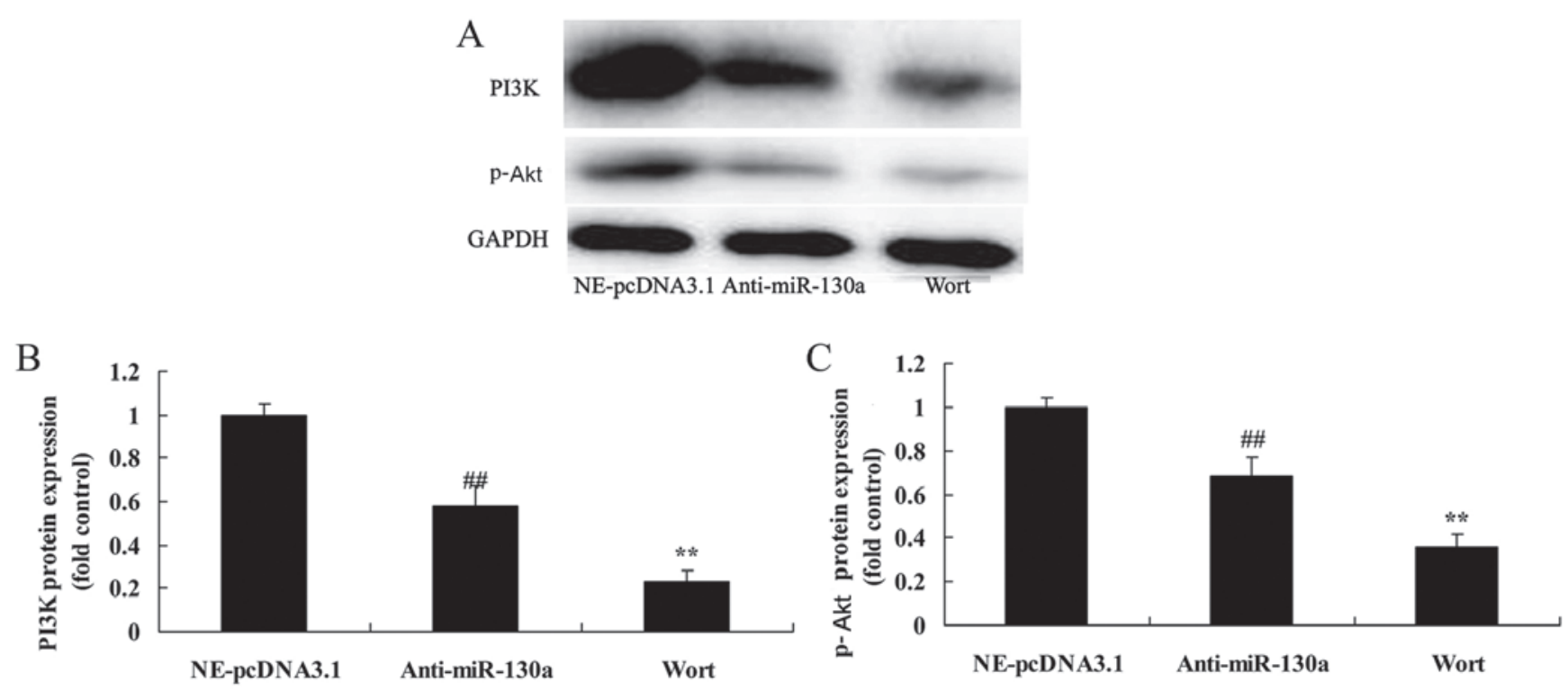

Figure 10. Wortmannin increases the destructive effect of microRNA-130a on PI3K/Akt signaling pathway of chondrocytes. Wortmannin increased the destructive effect of microRNA-130a on PI3K and p-Akt protein expression using western blotting (A) and statistical analysis for PI3K (B) and p-Akt (C) protein expression in chondrocytes. ${ }^{\# \#} \mathrm{p}<0.01$ compared with negative group; ${ }^{* *} \mathrm{p}<0.01$ compared with anti-microRNA-130a mimics group. Ne-pcDNA3.1, negative group; anti-miR-130a, anti-microRNA-130a mimics group; wortmannin, PI3K inhibitor group.

Activation of PI3K signal transduction pathway has been recently recognized to be one of the important mechanisms for anti-apoptosis of cells and induction of abnormal proliferation. PI3K/Akt signal pathway is closely associated with inflammation-associated cytokines, such as TNF- $\alpha$, IL-1, IL-6 and NF- $\mathrm{KB}$, and plays an important role in pathological process (20). PI3K can be activated by multiple extracellular stimuli, such as cytokines, growth factors, G-protein, T-cell antigen, small G-protein, thrombin, cytoplasmic protein tyrosine kinase, as well as other physical and chemical factors (21). In addition, it can induce extensive biological effects through PI3K/Akt pathway, and regulate multiple cell functions, such as apoptosis, proliferation, metabolism, growth and transformation, membrane transport, secretion and chemotaxis. Moreover, it plays an important role in the pathogeneses of inflammation, tumor, metabolic and cardiovascular diseases (17). Our data suggest that downregulation of microRNA-130a increased inflammation divisors in chondrocytes.

Akt is an effector of PI3K/Akt signal pathway locating in the important convergence point of multiple upstream signal activities (15). Akt is a serine/threonine protein kinase, the activation of which will induce the interaction between downstream phosphorylation cascade reaction and target proteins (22). On the contrary, it participates in the regulation 

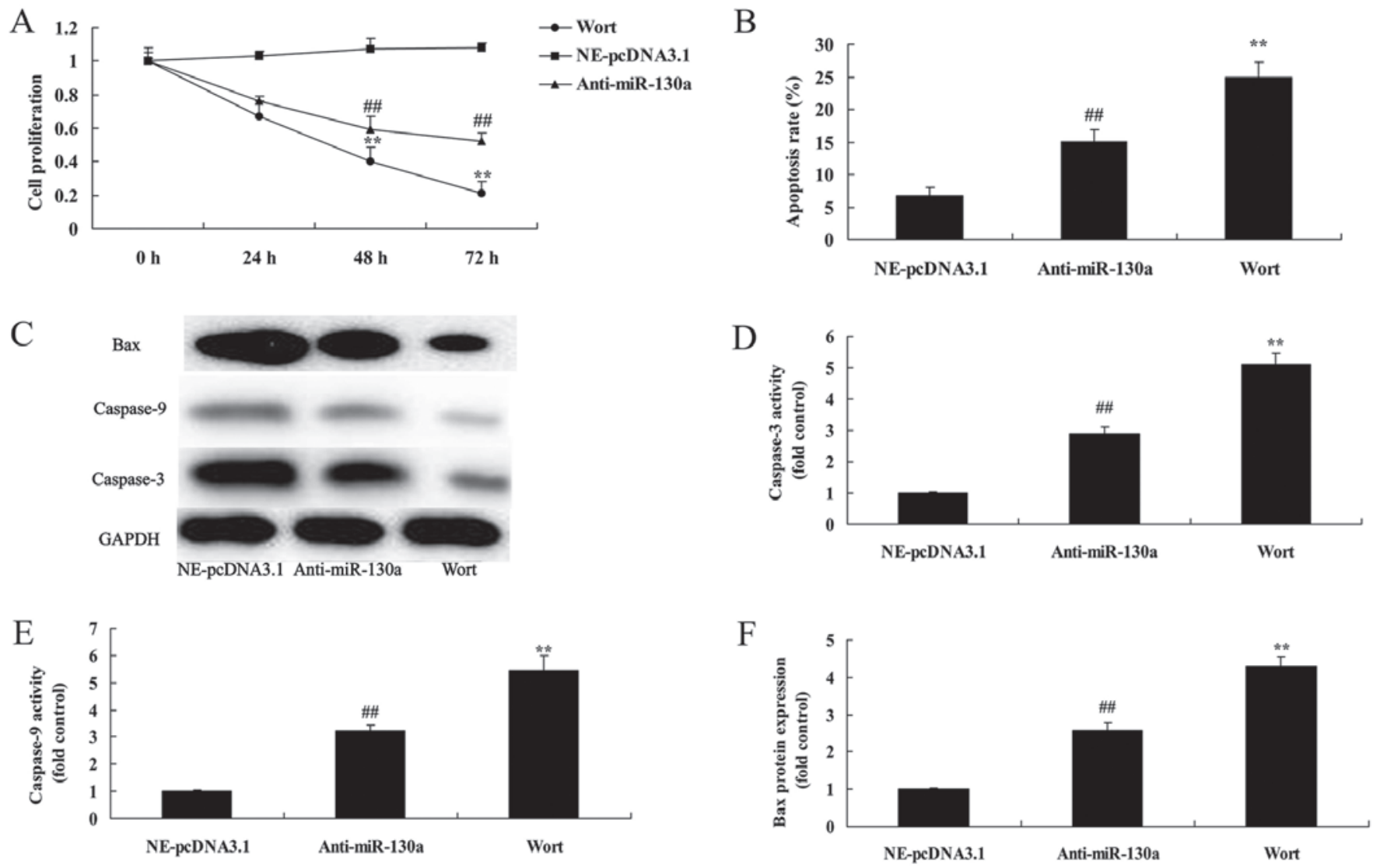

Figure 11. Wortmannin increases the destructive effect of microRNA-130a on cell proliferation of chondrocytes. Wortmannin increased the destructive effect of microRNA-130a on cell proliferation (A), apoptosis (B), Bax and caspase-3/9 protein expression using western blotting (C) and statistical analysis for Bax (D) and caspase-3/9 (E and F) protein expression in chondrocytes. ${ }^{\# \#} \mathrm{p}<0.01$ compared with negative group; ${ }^{* *} \mathrm{p}<0.01$ compared with anti-microRNA-130a mimics group. Ne-pcDNA3.1, negative group; anti-miR-130a, anti-microRNA-130a mimics group; wortmannin, PI3K inhibitor group.

A

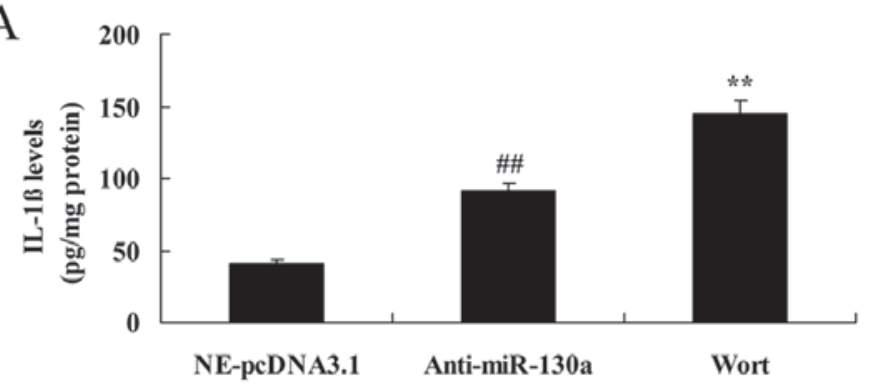

C
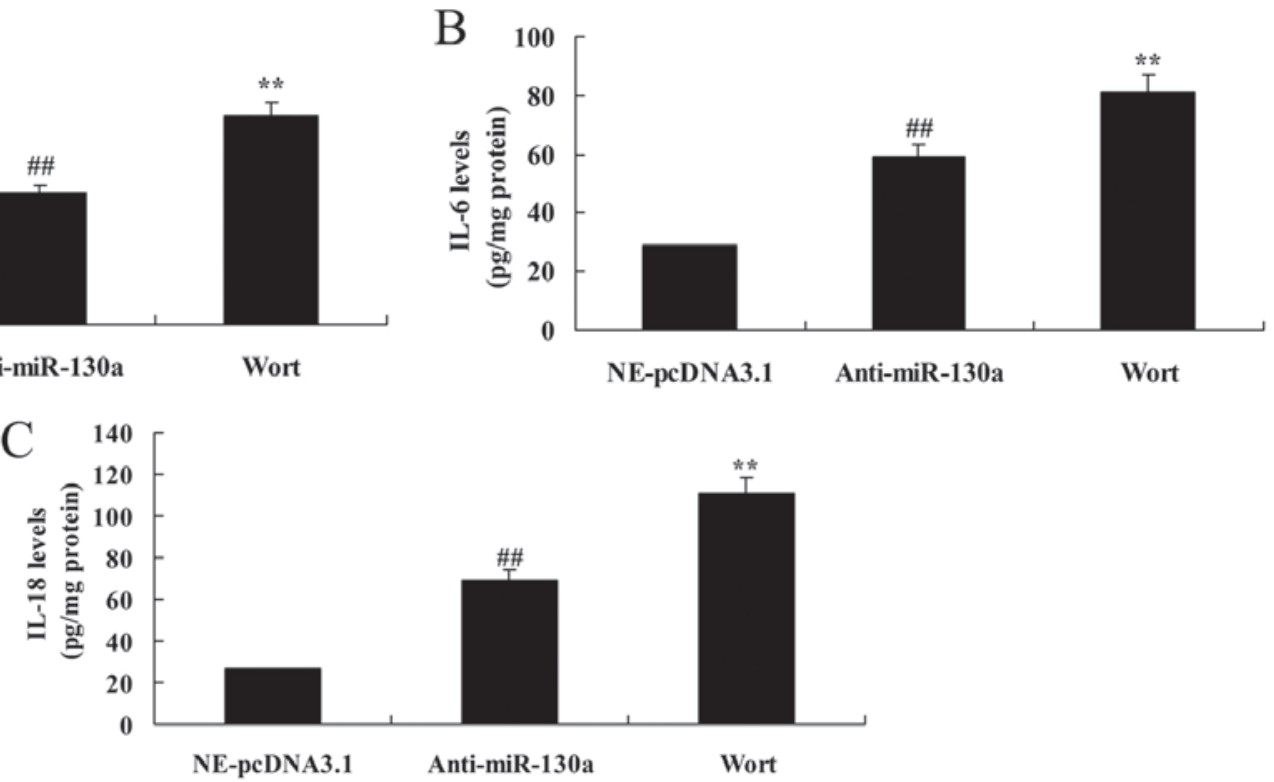

Figure 12. Wortmannin increases the destructive effect of microRNA-130a on inflammation divisors of chondrocytes. Interleukin-1 $\beta$ (IL-1 $\beta$ ) (A), IL-6 (B) and IL-18 (C) levels. ${ }^{\# \#} \mathrm{p}<0.01$ compared with negative group; ${ }^{* *} \mathrm{p}<0.01$ compared with anti-microRNA-130a mimics group. Ne-pcDNA3.1, negative group; anti-miR-130a, anti-microRNA-130a mimics group; wortmannin, PI3K inhibitor group.

of multiple biological effects, such as cell growth and survival, proliferation and apoptosis, carbohydrate metabolism, gene transcription, neovascularization, cell migration and movement, as well as cell cycle regulation (22). This study extends 
these observations suggesting that the downregulation of microRNA-130a significantly suppressed the PTEN/PI3K/Akt signaling pathway in chondrocytes.

Akt can also indirectly act on proteins or cytokines such as Bax, p53 and NF- $\mathrm{B}$, thus affecting cell survival, growth and proliferation (12). Akt plays a vital role of blocking PI3K/Akt pathway activity through targeting Akt, thereby offering possibility to treat PI3K/Akt signal activation-related diseases (23). Our data suggest that wortmannin also increased the destructive effect of microRNA-130a on inhibition of cell proliferation and apoptosis of chondrocytes through PI3K/Akt signaling. Lu et al (24) reported that microRNA-130a attenuated cardiac dysfunction and remodeling after myocardial infarction via activation of PI3K/Akt signaling via suppression of PTEN expression. This study shows that microRNA-130a regulates $\mathrm{PI} 3 \mathrm{~K} / \mathrm{Akt}$ signaling in osteoarthritis model in vitro.

PTEN is a tumor suppressor gene possessing dual-phosphorylase activities, which is a natural inhibitor of PI3K/ Akt signal pathway (14). Downregulated PTEN expression and afunction can frequently be seen in multiple tumors (14). PTEN downregulates PI3K/Akt pathway, and inhibits a series of downstream anti-apoptosis, proliferation and invasion related signals through the dephosphorylation of PI3K (15). Furthermore, PTEN can reduce the phosphorylation levels of multiple key survival kinases, thus promoting apoptosis and inhibiting proliferation as well as infiltration (15). PTEN reduces key protein activity through dephosphorylation, and blocks multiple signal pathways that promote tumor growth, invasion, metastasis and anti-apoptosis (25). It is pointed out in literature that PTEN gene mutation or methylation cannot be detected in RA synoviocytes, but PTEN has significantly lowered activity than normal level (25). In our assays, we found that PTEN inhibitor, decreased the destructive effect of microRNA-130a on cell proliferation and apoptosis of chondrocytes. Song et al indicated that miR-130a alleviates coronary artery endothelial cell injury through downregulating PTEN and activating PI3K/Akt/eNOS signaling pathway (26). This study extends these observations suggesting that miR-130a/ PTEN/PI3K/Akt signaling pathway participated in osteoarthritis apoptosis.

In conclusion, this study found that microRNA-130a targets PTEN and PI3K/Akt signal to regulate osteoarthritis-induced apoptosis and inflammation, which mediates the establishment and development of osteoarthritis. These results provide insights into the mechanism underlying directed differentiation of osteoarthritis.

\section{Acknowledgements}

Not applicable.

\section{Funding}

The study was supported by the Natural Science Foundation of China (no. 81472144).

\section{Availability of data and material}

The analyzed data sets generated during the study are available from the corresponding author on reasonable request.

\section{Authors' contributions}

YY designed the study. YZ, SX, EH, HZ, BL and CS performed the experiments. YY and YZ analyzed the data. YY wrote the manuscript. All authors read and approved the final manuscript.

\section{Ethics approval and consent to participate}

This study was carried out in accordance with the approved guidelines of Shanghai Tongji Hospital.

\section{Consent for publication}

Not applicable.

\section{Competing interests}

The authors declare that they have no competing interests.

\section{References}

1. Wallenstein GV, Kanik KS, Wilkinson B, Cohen S, Cutolo M, Fleishmann R, Genovese MC, Gomez Reino J, Gruben D, Kremer J, et al: Effects of the oral Janus kinase inhibitor tofacitinib on patient-reported outcomes in patients with active rheumatoid arthritis: Results of two phase 2 randomised controlled trials. Clin Exp Rheumatol 34: 430-442, 2016.

2. Izumi K, Kaneko Y, Hashizume M, Yoshimoto K and Takeuchi T: Baseline serum osteopontin levels predict the clinical effectiveness of tocilizumab but not infliximab in biologic-naïve patients with rheumatoid arthritis: A single-center prospective study at 1 year (the Keio First-Bio Cohort study). PLoS One 10: e0145468, 2015.

3. Xu Y, Zhu Q, Song J, Liu H, Miao Y, Yang F, Wang F, Cheng W, $\mathrm{Xi} Y$, Niu X, et al: Regulatory effect of iguratimod on the balance of Th subsets and inhibition of inflammatory cytokines in patients with rheumatoid arthritis. Mediators Inflamm 2015: 356040, 2015.

4. Durez P, Vandepapeliere P, Miranda P, Toncheva A, Berman A, Kehler T, Mociran E, Fautrel B, Mariette X, Dhellin O, et al: Therapeutic vaccination with TNF-Kinoid in TNF antagonistresistant rheumatoid arthritis: A phase II randomized, controlled clinical trial. PLoS One 9: e113465, 2014.

5. Genovese MC, Kremer J, Zamani O, Ludivico C, Krogulec M, Xie L, Beattie SD, Koch AE, Cardillo TE, Rooney TP, et al: Baricitinib in patients with refractory rheumatoid arthritis. N Engl J Med 374: 1243-1252, 2016

6. Maeda Y, Farina NH, Matzelle MM, Fanning PJ, Lian JB and Gravallese EM: Synovium-derived microRNAs regulate bone pathways in rheumatoid arthritis. J Bone Miner Res 32: 461-472, 2017.

7. Krintel SB, Dehlendorff C, Hetland ML, Hørslev-Petersen K, Andersen KK, Junker P, Pødenphant J, Ellingsen T, Ahlquist P, Lindegaard HM, et al: Prediction of treatment response to adalimumab: A double-blind placebo-controlled study of circulating microRNA in patients with early rheumatoid arthritis. Pharmacogenomics J 16: 141-146, 2016.

8. Abou-Zeid A, Saad M and Soliman E: MicroRNA 146a expression in rheumatoid arthritis: Association with tumor necrosis factor-alpha and disease activity. Genet Test Mol Biomarkers 15: 807-812, 2011.

9. Yang G, Wu D, Zeng G, Jiang O, Yuan P, Huang S, Zhu J, Tian J, Weng Y and Rao Z: Correlation between miR-126 expression and DNA hypomethylation of $\mathrm{CD}^{+} \mathrm{T}$ cells in rheumatoid arthritis patients. Int J Clin Exp Pathol 8: 8929-8936, 2015.

10. Jiang Y and Wang L: Role of histone deacetylase 3 in ankylosing spondylitis via negative feedback loop with microRNA-130a and enhancement of tumor necrosis factor-1 $\alpha$ expression in peripheral blood mononuclear cells. Mol Med Rep 13: 35-40, 2016.

11. Li ZC, Han N, Li X, Li G, Liu YZ, Sun GX, Wang Y, Chen GT and Li GF: Decreased expression of microRNA-130a correlates with TNF- $\alpha$ in the development of osteoarthritis. Int J Clin Exp Pathol 8: 2555-2564, 2015. 
12. Kuuliala K, Kuuliala A, Hämäläinen M, Koivuniemi R, Kautiainen H, Moilanen E, Repo H and Leirisalo-Repo M: Impaired Akt phosphorylation in monocytes of patients with rheumatoid arthritis. Scand J Immunol 85: 155-161, 2017.

13. Zhang W, Du Z, Zhu J, Yu J and Xu Y: Sprouty2 suppresses the inflammatory responses in rheumatoid arthritis fibroblast-like synoviocytes through regulating the Raf/ERK and PTEN/AKT signals. Mol Immunol 67: 532-539, 2015.

14. Wang CR, Shiau AL, Chen SY, Lin LL, Tai MH, Shieh GS, Lin PR, Yo YT, Lee CH, Kuo SM, et al: Amelioration of collagen-induced arthritis in rats by adenovirus-mediated PTEN gene transfer. Arthritis Rheum 58: 1650-1656, 2008.

15. Malemud CJ: The PI3K/Akt/PTEN/mTOR pathway: A fruitful target for inducing cell death in rheumatoid arthritis? Future Med Chem 7: 1137-1147, 2015.

16. Østergaard M, Jacobsson LT, Schaufelberger C, Hansen MS, Bijlsma JW, Dudek A, Rell-Bakalarska M, Staelens F, Haake R, Sundman-Engberg B, et al: MRI assessment of early response to certolizumab pegol in rheumatoid arthritis: A randomised, double-blind, placebo-controlled phase IIIb study applying MRI at weeks 0,1,2, 4, 8 and 16. Ann Rheum Dis 74: 1156-1163, 2015.

17. Zhu Q, Huang J, Wang SZ, Qin ZH and Lin F: Cobrotoxin extracted from Naja atra venom relieves arthritis symptoms through anti-inflammation and immunosuppression effects in rat arthritis model. J Ethnopharmacol 194: 1087-1095, 2016.

18. McWilliams DF, Ferguson E, Young A, Kiely PD and Walsh DA: Discordant inflammation and pain in early and established rheumatoid arthritis: Latent Class Analysis of Early Rheumatoid Arthritis Network and British Society for Rheumatology Biologics Register data. Arthritis Res Ther 18: 295, 2016.

19. Zumbrennen-Bullough KB, Wu Q, Core AB, Canali S, Chen W, Theurl I, Meynard D and Babitt JL: MicroRNA-130a is up-regulated in mouse liver by iron deficiency and targets the bone morphogenetic protein (BMP) receptor ALK2 to attenuate BMP signaling and hepcidin transcription. J Biol Chem 289 23796-23808, 2014
20. Jia Q, Cheng W, Yue Y, Hu Y, Zhang J, Pan X, Xu Z and Zhang P: Cucurbitacin $\mathrm{E}$ inhibits TNF- $\alpha$-induced inflammatory cytokine production in human synoviocyte MH7A cells via suppression of PI3K/Akt/NF- $\mathrm{BB}$ pathways. Int Immunopharmacol 29: 884-890, 2015.

21. Tang TT, Song Y, Ding YJ, Liao YH, Yu X, Du R, Xiao H, Yuan J, Zhou ZH, Liao MY, et al: Atorvastatin upregulates regulatory $\mathrm{T}$ cells and reduces clinical disease activity in patients with rheumatoid arthritis. J Lipid Res 52: 1023-1032, 2011.

22. Gao J, Zhou XL, Kong RN, Ji LM, He LL and Zhao DB: microRNA-126 targeting PIK3R2 promotes rheumatoid arthritis synovial fibro-blasts proliferation and resistance to apoptosis by regulating PI3K/AKT pathway. Exp Mol Pathol 100: 192-198, 2016.

23. Zhu X, Song Y, Huo R, Zhang J, Sun S, He Y, Gao H, Zhang M, Sun $\mathrm{X}$, Zhai T, et al: Cyr61 participates in the pathogenesis of rheumatoid arthritis by promoting proIL- $1 \beta$ production by fibroblast-like synoviocytes through an AKT-dependent NF- $\kappa \mathrm{B}$ signaling pathway. Clin Immunol 157: 187-197, 2015.

24. Lu C, Wang X, Ha T, Hu Y, Liu L, Zhang X, Yu H, Miao J, Kao R, Kalbfleisch J, et al: Attenuation of cardiac dysfunction and remodeling of myocardial infarction by microRNA-130a are mediated by suppression of PTEN and activation of PI3K dependent signaling. J Mol Cell Cardiol 89: 87-97, 2015.

25. Lee SH, Park JS, Byun JK, Jhun J, Jung K, Seo HB, Moon YM, Kim HY, Park SH and Cho ML: PTEN ameliorates autoimmune arthritis through down-regulating STAT3 activation with reciprocal balance of Th17 and Tregs. Sci Rep 6: 34617, 2016

26. Song CL, Liu B, Shi YF, Liu N, Yan YY, Zhang JC, Xue X, Wang JP, Zhao Z, Liu JG, et al: MicroRNA-130a alleviates human coronary artery endothelial cell injury and inflammatory responses by targeting PTEN via activating PI3K/Akt/eNOS signaling pathway. Oncotarget 7: 71922-71936, 2016 